DOI: 10.11606/issn.2238-3867.v16i1p55-70

sala preta

ppgac

Dossiê Performatividades Originárias

\title{
Estação Primeira de Mangueira: tradição, identidade e simultaneidade
}

\author{
Estação Primeira de Mangueira: tradition, \\ identity and simultaneity
}

\section{Carlos Eduardo Silva}

Carlos Eduardo Silva Ator, bonequeiro, iluminador e diretor teatral. Doutorando em Literatura pelo Programa de Pós-graduação em Literatura da Universidade

Federal de Santa Catarina (PPGLIT/UFSC)

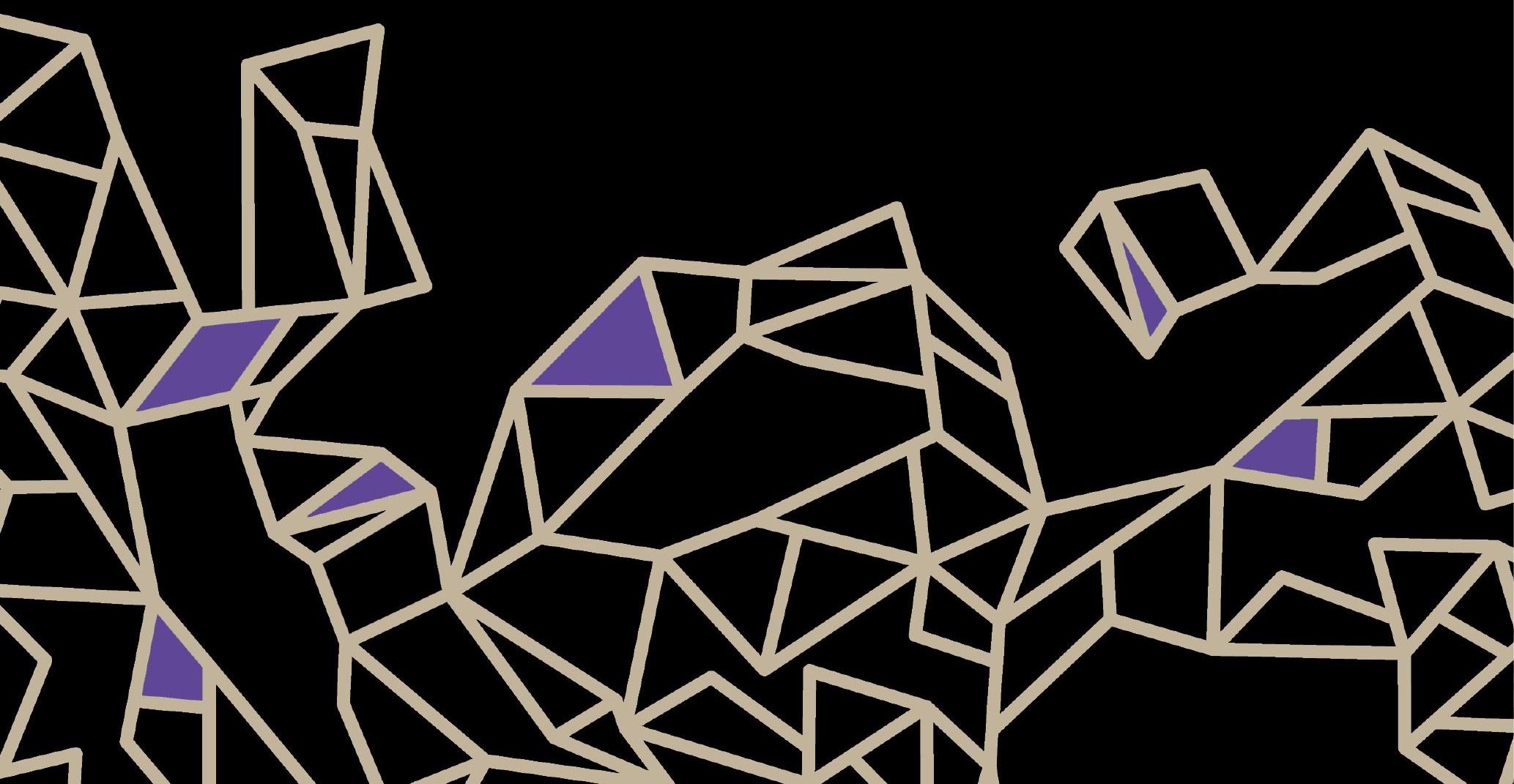




\section{Resumo}

Este artigo elabora uma leitura do carnaval campeão de 2016 da Estação Primeira de Mangueira sobre Maria Bethânia, com dois enfoques principais: como a performance do desfile articula a restauração enquanto elemento imprescindível na construção da noção de tradição e consolidação da identidade dessa escola de samba; e o espetáculo do desfile como um conjunto de eventos simultâneos. Para tanto, recorre-se a Agamben, Bakhtin, Benjamin, Lehmann, Moreno, Schechner e Winnicott; também se reflete sobre questões da memória e cultura e os aspectos que potencializam o brincar carnavalesco.

Palavras-chave: Carnaval, Mangueira, Tradição, Identidade, Simultaneidade.

\section{Abstract}

This paper presents a reading of the 2016 champion carnival of Estação Primeira de Mangueira, about Maria Bethânia, with two main focuses: how the performance of the parade articulates the restoration as a necessary element in the construction of the notion of tradition and identity consolidation of this samba school; and the performance of the parade as a set of simultaneous events. The article calls upon Agamben, Bakhtin, Benjamin, Lehmann, Moreno, Schechner and Winnicott; it also reflects on issues of memory and culture and the aspects that enhance the carnival play.

Keywords: Carnival, Mangueira, Tradition, Identity, Simultaneity. 


\section{A superação e o resgate da tradição}

Carlos cachaça, o menestrel

Mestre cartola, o bacharel

Seu delegado, um dançarino,

Faz coisas que aprendeu

Com Marcelino

E onde é que se juntam o passado, o futuro e o presente? ${ }^{1}$

Quem me chamou? Mangueira

chegou a hora, não dá mais p'ra segurar

Quem me chamou? Chamou pra sambar

Não mexe comigo, eu sou a menina de Oyá

"Estação Primeira" foi um epíteto cunhado por Cartola para dizer que após a Central do Brasil, a Estação de trem existente em Mangueira era a primeira a ter samba. Neste ano de 2016, a Mangueira foi novamente campeã do carnaval carioca e resgatou o simbolismo do título criado pelo seu fundador. Diz a grande mídia que a escola não ganhava desde 2002, mas prefiro pensar que a escola vinha perdendo desde 2008. Naquele ano, morria Jamelão, intérprete oficial da Verde e Rosa, a voz do samba e um dos maiores intérpretes da música popular brasileira. De luto, a escola tinha pela frente o centenário do seu fundador, Agenor de Oliveira, o já citado Cartola. Tema certo para um enredo redentor, enaltecendo as próprias raízes e um grande poeta do samba. Por razões financeiras a diretoria absteve-se da aguardada homenagem devido ao patrocínio recebido para se contar os cem anos do frevo. Ali algo se fraturou na relação entre a Estação Primeira de Mangueira e a noção de tradição que movia sua legião de apaixonados.

Após esse grave e inesquecível equívoco, a Supercampeã ${ }^{3}$ sofreu outras perdas e incidentes: morreram o diretor de harmonia, Xangô da Manguei-

1 Os meninos da mangueira, de Rildo Hora e Sérgio Cabral (1975).

2 Maria Bethânia, a menina dos olhos de Oyá, de Alemão do Cavaco, Almyr, Cadu, Lacyr D Mangueira, Paulinho Bandolim e Renan Brandão (2015).

3 Em 1984 inaugurou-se a passarela do samba Marquês de Sapucaí, projetada (arquitetonicamente) por Oscar Niemeyer e pelo antropólogo Darcy Ribeiro. Por consequência desse 
ra e o inesquecível mestre-sala Delegado; a admirada cantora Beth Carvalho foi desrespeitosamente expulsa de um desfile; os magníficos Marquinhos e Giovanna abandonaram o posto de casal oficial de mestre-sala e porta-bandeira; e membros da diretoria foram indiciados pela polícia fluminense por envolvimento com o narcotráfico, apenas para citar alguns fatos. Vieram uma sequência de enredos inexpressivos e resultados que revelavam uma constante ameaça de rebaixamento.

Vários ocorridos ampliaram o desgosto do mangueirense com os rumos de sua agremiação, que pareciam levar a mais tradicional escola de samba do Rio de Janeiro para o mesmo caminho do também prestigioso Império Serrano, que encara uma insuperável sequência de problemas, culminantes com sua estagnação no grupo de acesso. Tudo isso fez que a comunidade e os torcedores amantes da Verde e Rosa dispersassem e perdessem a esperança de ver a velha e arrebatadora Manga de volta.

Mas, no dia 9 de fevereiro de 2016, por volta das $4 \mathrm{~h}$ da manhã, algo aconteceu e reverteu essa trajetória de queda livre. Uma mística se fez presente e um encantamento nos levou todos de volta a 1984, quando a Mangueira também desfilava por último, já na terça-feira gorda, cantando Braguinha. Naquele ano a escola foi até a praça da Apoteose (também chamada de "Dispersão") - onde normalmente os componentes despedem-se do desfile e voltou para a avenida num movimento inédito até os dias atuais. Ou poderia ter sido em 1990, quando "Deu a louca no barroco" não venceu, mas ficou na memória como uma festa sem igual. Também parecíamos ter voltado a 1986, exaltando o baiano Dorival Caymmi com o inesquecível "tem xinxim e acarajé / tamborim e samba no pé [...]"4, pisando na avenida não para ganhar, apenas para brincar.

marco, aquele foi o primeiro ano que os desfiles foram divididos em dois dias, domingo e segunda-feira. Extraordinariamente, cada dia teve uma campeã, Portela naquele domingo e Mangueira no dia seguinte. No sábado, desfilariam as campeãs junto das demais primeiras colocadas; e uma nova competição ocorreu, em que a campeã ganharia a alcunha de supercampeã. Com o enredo "Yes, nós temos Braguinha!," a Mangueira foi campeã da segunda-feira e do sábado, acumulando os dois títulos daquele ano, por isso, muitos veículos de comunicação apontam erroneamente que a vitória de 2016 foi seu 180 título, pois não contam o supercampeonato. Contudo, a Liesa (Liga das Escolas de Samba do Rio de Janeiro) confirma 19 títulos.

4 Caymmi mostra ao mundo o que a Bahia e a Mangueira têm, de Ivo Meirelles, Paulinho e Lula (1986). 
Mas agora o tema da brincadeira foi outra baiana: Maria Bethânia, um grande expoente da MPB. Irmã de Caetano, ela foi o ponto de encontro com as religiões de matrizes africanas, em especial o candomblé, o sincretismo, a figura de Santa Bárbara, lansã ou Oyá, numa louvação da diversidade religiosa brasileira em tempos de intolerância e fundamentalismo. Foi tempo de rever a rica cultura do Recôncavo Baiano - local de origem da filha de Dona Canô - e a bela relação da própria cantora com a história da música brasileira.

Não era o carnaval de Bethânia, era o carnaval de todos os anos felizes da Mangueira, todas as glórias, todas as alegrias; era uma brincadeira, uma legião de brincantes extravasando na avenida. Num espaço que ultrapassava os limites do físico, num tempo que se encontrava com todos os anos do passado e apontava para um futuro alegre, debaixo de uma mangueira frondosa, em dia de sol, com os grandes velhos mangueirenses do passado de volta, comendo uma deliciosa feijoada, bebericando uma gelada cerveja e improvisando numa divertida roda de samba.

A partir de então, tudo mudou. Jamelão e Luizito cantaram pela voz de Ciganarey; mestre Waldomiro regeu novamente a bateria de Rodrigo Explosão; Raphael e Squel ${ }^{5}$ dançaram respectivamente como Neide e Delegado, empunhando a respeitada bandeira verde com raios cor-de-rosa; Dona Zica e tia Neuma encarnaram o espírito das matriarcas do samba nas também amadas Alcione e Beth Carvalho. E, finalmente, Cartola, Carlos Cachaça, Nelson Cavaquinho e toda a plêiade dos velhos fundadores e baluartes fizeram as pazes com a Mangueira e abençoaram aquele desfile.

O carnavalesco Leandro Vieira foi competente em transformar os mais de quatro mil e quinhentos (4.500) integrantes em brincantes. Criou um enredo simples e facilmente lido por alegorias belas e usadas na proporção adequada para não inviabilizar a comunicação; desenhou fantasias criativas e volumosas sem tirar a liberdade corporal dos desfilantes. A diretoria parecia entrosada e atuando como um time, sem sufocar a grande brincadeira com uma excessiva organização.

Vieira entrou para a história como o primeiro carnavalesco a estrear no Grupo Especial, em plena Marquês de Sapucaí, como campeão. O carnava-

5 A porta-bandeira oficial, Squel Jorgea, é neta do inolvidável diretor de harmonia Xangô da Mangueira. 
lesco não trouxe nenhuma inovação estética ao desfile, como Joãozinho Trinta, que compreendeu a verticalização que a passarela do samba impunha às escolas - em função de suas arquibancadas elevadas e deslocadas da avenida - e elaborou carros alegóricos cada vez mais altos para os padrões até então adotados. Nem como Paulo Barros, que explorou aspectos da presença humana, o impacto das alas coreografadas, a utilização de carros alegóricos vivos, completados apenas na execução da avenida, em detrimento da noção das alegorias tidas como obras de artes completas que chegavam prontas e acabadas para o desfile.

Barros injetou porosidade aos desfiles, investindo na noção de inacabamento físico, dinamizou o evento, fugindo da zona de conforto do realizado pelos demais carnavalescos ano a ano e, para gerar impacto na audiência, empregou aspectos de teatralização, espetacularizando a ocupação das alegorias e adaptando a estratégia usada nos eventos, que colocam centenas de pessoas em cena agindo com milimétrica articulação e entrosamento na produção de um efeito estético impactante - como ocorre nas comunistas China, Coréia do Norte e na antiga União Soviética. Assim, potencializou e investiu no eixo de comunicação plateia/desfilante. Se Joãozinho fez a escola de samba subir as arquibancadas para ser vista pela audiência, Barros deu nova qualidade ao ato, fazendo o público dialogar com as alegorias vivas e presentificando a manifestação.

Mas foi Leandro Vieira que fez essa relação se tornar contagiante. Pois as alegorias, seja com movimento e vida seja como escultura estática, ainda são elementos de exposição. Antes, como agora, servem para ser vistas, impõem ao público o papel de observador. Ocorre que, mesmo sem a qualidade dinâmica das alegorias de Barros, Vieira intensificou o aspecto presencial do desfile ao adicionar um novo ingrediente a essa poção: a brincadeira. Assim, para Gumbrecht (2010) a produção da presença é mais do que reconhecer a existência do público e dos desfilantes da Mangueira, mas reconhecê-los como sujeitos da brincadeira, como agentes e partes ativas do processo lúdico. Aí se completou a grande magia.

Enfim, a Mangueira parecia uma escola pensada para brincar e por isso ganhou não apenas o campeonato, mas recuperou sua tradição. Mas o que é tradição nesse contexto? Poderíamos dizer que tradição são todas as recordações de eventos e pessoas que fizeram parte do carnaval carioca através 
da Verde e Rosa e são resgatados e invocados ano após ano em cada desfile. Como diz o samba exaltação: "A Mangueira não morreu, nem morrerá, isso não acontecerá [...] Mangueira, teu passado de glória está gravado na história"'. A memória é a própria matéria-prima da tradição, imprecisa, intensiva e parte do nosso sistema de afetos, que encontra a completude na coletividade. Tal como propõe Benjamin (1994), a memória é fragmentária, evocada em pulsos, em cacos, contudo, a coletividade se encarrega de preencher as lacunas que as fontes individuais possuem.

A tradição, portanto, não é estática, ganha contornos de ficção quanto mais incerta se torne a lembrança e pode virar um fato realmente vívido, colorido pelo desejo nem sempre realizado naquela experiência, como um querer misturado à realidade. Para uma escola de samba, a tradição se move, cresce com outras experiências na repetição de suas práticas anuais e se torna um patrimônio que é motivo de orgulho e reverência por quem o reconhece, que alça à imortalidade e a uma forma de mitologia contemporânea todos aqueles envolvidos. A tradição serve tanto ao sistema de identificação imediata da Estação Primeira de Mangueira para o seu torcedor quanto para a imagem que aquela comunidade faz de seus feitos. Conforme diz o samba-enredo de 1993:
[...] Entre tantos tipos de mangueira
há uma especial...
na Estação Primeira
ela simboliza o samba
é a união de gente bamba
onde desabrocham tantas flores $[\ldots]^{7}$

A performatividade inerente ao processo de feitura do carnaval e de sua complementação na avenida articula vários elementos, em especial, atua na direção da restauração dos inúmeros saberes envolvidos nos procedimentos carnavalescos e os une num tempo e espaço compartilhados e coabitados por aqueles mesmos ícones do passado. O desfile de 2016 produziu esse

6 Exaltação à Mangueira, de Enéas Brittes da Silva e Aloísio Augusto da Costa.

7 Dessa fruta eu como até o caroço, de Bira do Ponto, Eraldo Caê, Verinha, Dirceu, Preto, Fernando Lima, Gustavo e Ney Mattos (1993). 
efeito, resgatou a tradição mangueirense como ponto de encontro dos mestres e feitos do passado com os brincantes do presente.

Ao mesmo tempo em que a performance carnavalesca resgata um passado romantizado e revive uma memória no presente, ela estabelece novas habilidades e destrezas relacionadas à eficácia de se fazer ressurgir no tempo atual o tempo pregresso. Assim, a tradição se consolida numa prática de reconstituição, mas também cria novas experiências, aptidões e memórias que se imortalizam no imaginário coletivo. $O$ mundo do samba aprendeu que a tradição é um patrimônio imaterial, que não ganha carnaval de véspera e nem pode estagnar um coletivo, por isso deve atualizar-se no tempo e acumular novos frutos, segundo profetizou Cartola:

Guerreei na juventude

Fiz por você o que pude,

Mangueira [...]

E no fim desse labor

Surge outro compositor

Com o mesmo sangue na veia. ${ }^{8}$

\section{Oposição, simultaneidade e parataxe: a menina dos olhos de Oyá}

[...] O palco se ilumina

Tudo é brilho, luz e cor

Mergulhei na poesia

Drama, riso e fantasia

Num cenário multicor Surgiu de uma era distante

Esta arte fascinante

Que o mundo inteiro deslumbrou

Com encanto e magia

O teatro irradia

A mais pura emoção

8 Fiz por você o que pude, de Cartola. 
E, hoje, esta beleza infinita

Acontece na Avenida [... ${ }^{9}$

[...] E transformou toda mentira

Na mais fiel realidade

Vai...

Contar a história do infinito

Vai...

Não haverá amanhecer

Vai dizer que foi esculturada

Que sofreu por amor

E foi amada

Musa inspiradora

Luz de uma canção

Bailando na imensidão $[\ldots]^{10}$

Um desfile de carnaval se faz sobre uma zona de liminaridade, segundo a interpretação de Caballero (2011). Uma zona que articula incontáveis conceitos, procedimentos e fenômenos coincidentes ou paradoxais, opositores ou similares, onde se produz subversão e profanação de valores, de acordo com Agamben (2007), e se cruzam temas e interesses dos mais diversos: conteúdos históricos, debates políticos, manifestações de protesto. Tudo isso é materializado na música, corporificadas no canto, inspirando fantasias e alegorias, gerando movimentos e coreografias, estabelecendo novas estruturas de relacionamento nos envolvidos entre si e entre eles e a performance, ou seja, novas arquitetônicas, segundo Bakhtin. Fundem-se teatralizações, performances e danças em plena evolução da procissão na avenida. E esses elementos coexistem e coabitam o mesmo espaço efemeramente... para tudo se acabar na quarta-feira.

Não por acaso, o próprio calendário encerra o carnaval com o início da quaresma, isto é, os quarenta dias em que Jesus jejuou e isolou-se no deser-

9 As mágicas luzes da ribalta, de Mazinho e Gilson Doutor (1987). Samba-enredo da Beija-flor de Nilópolis.

10 Deu a louca no barroco, de Hélio Turco, Jurandir e Alvinho. 
to para reaparecer oferecendo-se no sacrifício final que o levou a ressurgir no terceiro dia, coincidindo com a Páscoa, em cumprimento às profecias, tal qual apregoam as religiões de matrizes ditas cristãs. A relação do sagrado e do profano está no seio dos motivos carnavalescos, como seus próprios limites. Os ícones religiosos, o sincretismo afrodescendente, as divindades africanas coabitando o imaginário de herança católica. A mistura de culturas, ritmos e festas diversas (Parintins, maracatus, bumba meu boi, Cavalo Marinho etc.). O povo explorando limites diferentes dos convencionais.

O desfile cujo enredo foi "Maria Bethânia, a menina dos olhos de Oyá" apresentou esses aspectos da religiosidade da cantora, colocando na avenida elementos sagrados do catolicismo junto de expressões da cultura africana; trouxe um pouco das músicas que alçaram Bethânia ao sucesso, a relação com o Teatro Opinião e a cultura da região onde a baiana nasceu. A Mangueira amalgamou todos os componentes do seu enredo num evento que fundiu integrantes e plateia numa grande legião de brincantes. A razão pela qual o carnaval existe é para tornar-nos brincadores, não competidores. Algo além de toda estrutura pensada e planejada pelo poder público e o marketing televisivo com vistas a tornar o carnaval uma competição entre escolas de sambas, que apresenta um disputado concurso, com julgadores e seus quesitos.

A configuração de um desfile de escola de samba é bastante sui generis, comparando-a com a de outras manifestações performativo-culturais. No teatro, por exemplo, há uma variedade de palcos (italiano, elisabetano, arena, semiarena, rua etc.) e cada um deles estabelece uma forma particular de comunicação entre artistas e audiência. O que dizer então de um palco longitudinal? Isto é, a Marquês de Sapucaí é uma avenida de 800 metros, onde a apresentação se dá na forma de um cortejo que prossegue na direção do final da pista. O público situa-se em arquibancadas dispostas por ambas as margens ao longo do comprimento desse "palco".

A apresentação é dinamicamente fluída, sequencial, tal qual uma procissão que só se estanca por breves momentos para apresentações isoladas de determinados elementos da escola diante da cabine dos jurados, continuando sua evolução posteriormente. Essa formação estabelece um sentido de continuidade. Espera-se que o carnavalesco aproveite essa sequência para estabelecer uma lógica que identifique o enredo com facilidade para o públi- 
co, respeitando uma certa estrutura inclusive prevista no regulamento, como a necessidade da ala de baianas, a comissão de frente, o casal porta-estandarte, a bateria, a velha guarda, a ala das crianças, dos compositores etc.

Porém, a lógica sequencial não impõe ao espectador uma leitura racional, com começo, meio e fim, numa leitura cartesiana coerente. O público é livre para olhar onde quiser, ou até deixar de olhar; ir ao banheiro; fazer um lanche; relacionar-se com o entorno. A relação sequencial do desfile é uma ilusão alimentada pela imposição que ocorre apenas para os telespectadores, que são sujeitos à perspectiva de uma câmera apontada para um mesmo foco e parada na torre de TV da avenida. Perde-se com isso tudo o que foge do captado por aquela lente, e mesmo quando filmado, há coisas que a tecnologia não consegue transmitir: a presença física (aurática), segundo Benjamin (1994), o olhar alheio, a expressão apaixonada, a emoção do canto etc.

Os acontecimentos não se dão nem se repetem de maneira igualitária pelo espaço e sim, sofrem a ação de diversos fatores que compõem aquilo que conhecemos no todo como "desfile." Um evento que se realize num determinado ponto da avenida pode não se repetir mais adiante. Um carro alegórico pode maravilhar um setor e quebrar metros depois, desfigurando todo o andamento das alas subsequentes. Pela variação do ângulo de visão, dependendo da posição, a audiência pode ter impressões diferentes do mesmo evento apresentado no desfile. O tempo de desfile decorrido tende a apressar ou retardar as ocorrências programadas para acontecerem nas últimas alas.

Só isso basta para percebermos que o desfile como um todo é formado por numerosos e simultâneos eventos que atraem de todos os lados a atenção e a operação da plateia: a comissão de frente se apresenta, enquanto mais atrás o casal de mestre-sala e porta-bandeira exibe-se, a arquibancada em frente reage com euforia a algo que daqui de onde estou não consigo ver, porém eu reajo não mais ao ocorrido, mas pelo contágio do público à frente (ou seja, o público, pela sua disposição frontal, também é parte do espetáculo) e tudo isso se dá simultaneamente. Essa noção aproxima-se do conceito de simultaneidade, apontado por Schechner (2002) como um dos elementos existentes na performance.

Pela perspectiva de Lehmann (2007), o desfile seria um evento paratático, produtor de vários pulsos sobrepostos ao longo da apresentação, equânimes 
ou distintos, permitindo ao espectador relacionar-se com aquele que mais intensamente Ihe afetar. O paralelismo com que as atividades se realizam manifesta também a concomitância desses pulsos e a infinidade de direcionamentos e leituras possíveis da distribuição do enredo. As construções semânticas sobre o desfile podem responder a variadas operações realizadas pelo público, conforme o ordenamento que cada um faz dos pulsos que tenham lhe estimulado.

Mas essa leitura não é condição imprescindível para a comunicação da escola de samba com a plateia. Não é muito relevante entender o desfile - ainda que isso não seja desprezado - e a postura crítica do público fica em segundo plano. Mas, tornar o público tão brincante quanto os integrantes da escola, essa seria a meta a ser atingida. O objetivo maior é sobrepor o sensível ao lógico, a experiência à crítica, e contagiar mais do que convencer. Um exemplo preciso desse conceito é a bateria da escola de samba: nem sempre se entende sua fantasia, o propósito dessa ou daquela paradinha, coreografia ou movimentos rítmicos, mas basta que ela passe para o público sentir uma pulsão sem paralelo.

Junto dessa exposição concomitante de diversos signos, um desfile apresenta muitas manifestações de oposição, como materialização do próprio conceito bakhtiniano de carnavalização, baseado na inversão de valores. O pobre, afrodescendente, é o rei, o mestre, o diretor, o mestre de cerimônias, numa antinomia que não se pretende vencer, é para ser assim. A performatividade do desfile carnavalesco expõe seus próprios mecanismos, não há intenção em fazer que o pobre pareça ou provoque a ilusão de ser a figura que represente em evocação ao enredo. É na diferença revelada que os opostos se denunciam e se destacam, nessa precariedade que o carnaval se instaura e as oposições se estabelecem.

\section{Comunidade: a construção da identidade mangueirense}

[...] Glória a quem trabalha o ano inteiro

Em mutirão

São escultores, são pintores, bordadeiras São carpinteiros, vidraceiros, costureiras Figurinista, desenhista e artesão Gente empenhada em construir a ilusão 
E que tem sonhos

Como a velha baiana

Que foi passista

Brincou em ala

Dizem que foi o grande amor de um mestre-sala [...]

Sonho de rei, de pirata e jardineira

Pra tudo se acabar na quarta-feira

Mas a quaresma lá no morro é colorida Com fantasias já usadas na avenida [... $]^{11}$

Segundo Moreno (1974), a identidade é uma construção individual realizada em grupo, a partir do aperfeiçoamento do papel social que um sujeito desempenha nesse coletivo (ou em todos os coletivos do qual faça parte). Pode ser o papel (a função) de escultor, pintor, bordadeira... por isso, a elaboração da identidade é um processo que envolve sempre o outro, a perspectiva do outro, em articulação com a do próprio agente. Essa ótica está relacionada com a performance de uma atividade importante para a comunidade, exige eficácia e perícia na sua execução. Não é uma relação apenas produtiva, mas funcional e que articula valores intersubjetivos relevantes para o grupo.

Por isso, os mestres de uma escola de samba são aqueles que cumprem efetivamente um papel, uma função importante dentro do grupo, e que carregam um saber envolvido numa destacada operação. Não raro, a atividade relacionada não tem a mínima importância na sociedade em geral, mas no microcosmo do agrupamento destacado é extremamente valorizada e significativa para se atingir o objetivo comum. Um mestre-sala é uma figura sem o menor prestígio fora do seu contexto, mas é imprescindível no universo carnavalesco, por exemplo. Assim, pessoas extremamente simples guardam saberes que eternizam os conhecimentos do carnaval de uma escola de samba e isso é parte da identidade deles e da instituição.

Winnicott (1975) aponta para uma visão que estabelece a construção da identidade mais a partir do brincar do que da utilidade social, ainda que na brincadeira o brincante exerça um papel próprio do jogo, com função dentro da

11 Pra tudo se acabar na quarta-feira, de Martinho da Vila (1984). Samba-enredo da Unidos da Vila Isabel. 
relação constituída. O pensamento de Winnicott tem origem no pensamento romântico de Schiller (1989), para quem o homem possui dois impulsos elementares: o sensível e o racional, que se tencionam, conciliam e se manifestam sem predomínio de um sobre o outro, numa zona transicional chamada impulso lúdico. Nessa mesma direção, Courtney (2006) afirmou que o animal tem mais energia do que necessita para os objetivos sérios da vida; assim o jogo é uma forma de consumo do excedente energético. O carnaval é um festejo para consumir as energias mundanas, para o corpo poder concentra-se nas "coisas do espírito", na meditação que os quarenta dias posteriores demanda.

Assim, para Winnicott, é na brincadeira que os impulsos sensíveis, desbloqueados de qualquer predominância racional, expressam-se livremente, gerando criatividade. É no brincar que se pode usufruir da liberdade de criação, ser criativo e buscar-se a realização integral da personalidade. É brincando que essa personalidade se elabora e uma identidade se constrói. Portanto, o brincar tem sua importância relacionada com a articulação da memória, da tradição num processo de restauração, consolidação da cultura e constituição da identidade e do que o indivíduo é e se torna, ou de como ele assina o território em que habita.

A Mangueira é uma comunidade que tanto possui fazeres específicos dominados por seus respectivos mestres quanto proporciona um brincar a partir deles. Em ambas as abordagens, a Verde e Rosa é um contexto profundo de criação de identidades que formam as individualidades de sua própria comunidade e que, por conseguinte, constitui a sua própria identificação enquanto instituição do samba.

Essa marca de contrários somada à romantizada vida boêmia e poesia de seus integrantes criou uma identificação com a própria realidade carioca e brasileira. Esse vínculo da escola para seu público se fortaleceu no decorrer dos anos, fazendo que a comunidade de Mangueira não seja mais apenas aquela formada pelos habitantes do complexo do morro homônimo, que congrega Tengo-Tengo, Santo Antônio, Chalé, Buraco Quente e outros.

Apenas para se ter uma ideia do quanto essa identidade cria empatia: a Mangueira nunca teve um bicheiro ou patrocinador, a exemplo de outras escolas. Por isso representava a pobreza que resistia e às vezes vencia o luxo, a alegria que desbancava a opulência, a precariedade que se completa na avenida levando à apoteose. Para a comunidade formada pelos amantes da 
Verde e Rosa, a identidade da escola é uma somatória dessas relações estabelecidas ao longo da história, algo inestimável e que vez por outra emerge num movimento mágico pela avenida, arrebatando corações e sendo coroado com a conquista de mais um campeonato.

\section{Referências bibliográficas}

AGAMBEN, G. Profanações. Tradução Selvino J. Assmann. São Paulo: Boitempo, 2007.

ALEMÃO DO CAVACO et al. Maria Bethânia, a Menina dos Olhos de Oyá. Intérprete: Ciganerey. In: SAMBA ENREDO 2016 - GRUPO ESPECIAL. São Paulo: Universal Musica, 2015. Faixa 10.

BIRA DO PONTO et al. Dessa fruta eu como até o caroço. Intérprete: Eraldo Caê. In: SAMBAS DE ENREDO 1993. [S.I.]: BMG, 1993. Lado B, faixa 3.

BENJAMIN, W. A Obra de arte na era de sua reprodutibilidade técnica. In:

Magia e técnica, arte e política: ensaios sobre Literatura e História da Cultura. Obras Escolhidas. v. 1. São Paulo: Brasiliense, 1994.

BRAIT, B. (Org.). Bakhtin: outros conceitos-chave. São Paulo: Contexto, 2010.

CABALLERO, I. D. Cenários liminares: teatralidades, performances e política. Uberlândia, MG: UDUFU, 2011.

CARTOLA. Fiz por você o que pude. Intérprete: Cartola. In: HISTÓRIAS DAS ESCOLAS DE SAMBA. Mangueira. São Paulo: Discos Marcus Pereira, 1974. Faixa 8.

COURTNEY, R. Jogo, Teatro \& Pensamento. Tradução Karen Astrid Müller e Silvana Garcia. 3 ed. São Paulo: Perspectiva, 2006.

GUMBRECHT, H. U. Produção de Presença: o que o sentido não consegue transmitir. Rio de Janeiro: PUC-Rio, 2010.

HÉLIO TURCO; JURANDIR; ALVINHO. E deu a louca no barroco. Intérprete: Jamelão. Participação especial: Sobrinho. In: SAMBAS DE ENREDO DAS ESCOLAS DE SAMBA DO GRUPO 1A. Carnaval 90. 1990. Lado B, faixa 2.

HORA, R.; CABRAL, S. Os meninos da Mangueira. Intérprete: Ataulfo Alves Jr. In: ATAULFO JR. Os meninos da mangueira. São Paulo: RCA Victor, 1975. Compacto. LEHMANN, H.-T. Teatro Pós-dramático. São Paulo: Cosac Naify, 2007.

MARTINHO DA VILA. Pra tudo se acabar na quarta-feira. Intérprete: Marcos Moran, Gera e Valcy. In: SAMBAS DE ENREDO DAS ESCOLAS DE SAMBA DO GRUPO 1A. Carnaval 84. 1984. Lado A, faixa 2.

MAZINHO; GILSON SR. As mágicas luzes da ribalda. Intérprete: Neguinho da Beija-flor. In: SAMBAS DE ENREDO 1987. 1987. Lado B, faixa 1. 
MEIRELLES, I.; PAULINHO; LULA. Caymmi mostra ao mundo o que a Bahia e a Mangueira têm. Intérprete: Jamelão e Lula. In: SAMBAS DE ENREDO ESPECIAL 1986. 1986. Lado B, faixa 2.

MORENO, J. L. Psicoterapia de Grupo e Psicodrama. São Paulo: Mestre Jou, 1974. SCHECHNER, R. Performance studies: an introduction. New York: Routledge, 2002. SCHILLER, F. A educação estética do homem: numa série de cartas. Tradução de

Roberto Schwarz e Márcio Suzuki. São Paulo: lluminuras, 1989.

SILVA, M. T. B. da; CACHAÇA, C.; OLIVEIRA FILHO, A. L. de O. Fala Mangueira. Rio de Janeiro: José Olympio, 1980.

WINNICOTT, D. W. O brincar e a realidade. Tradução José Octavio de Aguiar Abreu e Vanede Nobre. Rio de Janeiro: Imago, 1975.

Recebido em 18/03/2016

Aprovado em 18/05/2016

Publicado em 01/07/2016 